"This accepted author manuscript is copyrighted and published by Elsevier. It is posted here by agreement between Elsevier and MTA. The definitive version of the text was subsequently published in [Ceramics International, 2018, 44, 22976-22982.; DOI 10.1016/j.ceramint.2018.09.096]. Available under license CC-BY-NC-ND." 


\section{Synthesis and characterization of $\mathrm{Sr}$ and Mg-doped}

\section{hydroxyapatite by a simple precipitation method}

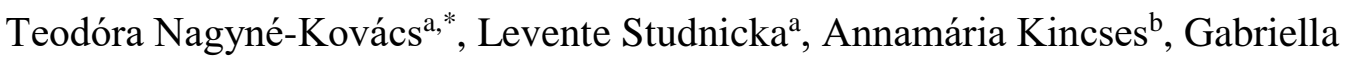

Spengler ${ }^{\mathrm{b}}$, Mónika Molnár ${ }^{\mathrm{c}}$, István Endre Lukács ${ }^{\mathrm{d}}$, Imre M. Szilágyi ${ }^{\mathrm{a}}$, György Pokol ${ }^{\mathrm{a}, \mathrm{e}}$

${ }^{a}$ Department of Inorganic and Analytical Chemistry, Budapest University of Technology and Economics, Müegyetem rakpart 3., Budapest, H-1111, Hungary

${ }^{b}$ Department of Medical Microbiology and Immunobiology, University of Szeged, Dóm tér 10., Szeged, H-6720, Hungary

${ }^{c}$ Department of Applied Biotechnology and Food Science, Budapest University of Technology and Economics, Müegyetem rakpart 3., Budapest, H-1111, Hungary

${ }^{d}$ Research Institute for Technical Physics and Materials Science, Hungarian Academy of Sciences, Konkoly Thege M. út 29-33, Budapest, H-1121 Hungary

${ }^{e}$ Research Centre for Natural Sciences, Hungarian Academy of Sciences, Magyar tudósok körútja 2., Budapest, H-1117, Hungary

*Corresponding author telephone number and e-mail: +361463 1216, kovacs.teodora@mail.bme.hu 


\section{ABSTRACT}

This study presents the preparation of pure, $\mathrm{Sr}$ and $\mathrm{Mg}$-doped hydroxyapatite (HAP) by precipitation. Sr-doped HAPs (SrHAPs) and Mg-doped HAPs (MgHAPs) were fabricated with $\mathrm{Sr}$ molar ratio of 2, 4, 6, 8, $12 \%$ and $\mathrm{Mg}$ molar ratio of 2, $4 \%$, respectively. $\mathrm{Ca}\left(\mathrm{NO}_{3}\right)_{2}, \mathrm{Sr}\left(\mathrm{NO}_{3}\right)_{2}, \mathrm{Mg}\left(\mathrm{NO}_{3}\right)_{2},\left(\mathrm{NH}_{4}\right)_{2} \mathrm{HPO}_{4}$ were used as starting materials, the $\mathrm{Ca} / \mathrm{P}$ molar ratio was kept 1.67 during every synthesis and a $900{ }^{\circ} \mathrm{C}$ heat treatment was conducted to enhance the crystallinity. All of the products were analyzed by XRD, SEM and EDX, moreover lattice parameters and crystallite size calculations were performed to prove the ion incorporation into the crystal structure. The HAP structure was maintained when 2 and $4 \mathrm{Sr}$ and $2 \mathrm{Mg} \%$ were applied and EDX confirmed the $\mathrm{Sr}$ and $\mathrm{Mg}$ content in these samples. In all other cases, various $\mathrm{Sr}$ and $\mathrm{Mg}$-containing phases $\left(\mathrm{Sr}_{0.13} \mathrm{Ca}_{2.87}\left(\mathrm{PO}_{4}\right)_{2}\right.$, $\left.\mathrm{Ca}_{2} \mathrm{P}_{2} \mathrm{O}_{7}, \mathrm{Mg}_{0.29} \mathrm{Ca}_{2.71}\left(\mathrm{PO}_{4}\right)_{2}\right)$ were identified while the HAP structure disappeared. It was shown that lattice parameters and the unit cell volume of Sr-doped HAPs increased slightly compared to pure HAP due to the bigger radius of $\mathrm{Sr}^{2+}$ than $\mathrm{Ca}^{2+}$. As the ionic radius of $\mathrm{Mg}^{2+}$ is smaller than $\mathrm{Ca}^{2+}$, we demonstrated the distortion in the unit cell. Crystallite sizes increased as the amount of $\mathrm{Sr}$ and $\mathrm{Mg}$ raised. SEM experiments demonstrated that ion incorporation had little influence on the morphology, i.e. pure, $\mathrm{Sr}$ or Mg-doped HAPs were mostly homogenous, constituted of strongly sintered nanometer sized grains. Antimicrobial tests indicated that SrHAP with $4 \mathrm{Sr} \%$ and MgHAP with 2 $\% \mathrm{Mg}$ had positive effect on cell viability.

\section{KEYWORDS}


$\mathrm{Sr}$ and Mg-doped hydroxyapatite, calcination, lattice parameters, crystallite size, antibacterial activity

\section{Introduction}

Natural hydroxyapatite (HAP, $\left.\mathrm{Ca}_{10}\left(\mathrm{PO}_{4}\right)_{6} \mathrm{OH}_{2}\right)$ is an essential compound of hard tissues in vertebrates, forming the inorganic part of its matrix. In natural bones and teeth the inorganic material constitutes mostly of $\mathrm{Ca}^{2+}, \mathrm{PO}_{4}{ }^{3-}$ and $\mathrm{OH}^{-}$ions, but others such as $\mathrm{HPO} 4{ }^{2-}, \mathrm{CO}_{3}^{2-}, \mathrm{Mg}^{2+}, \mathrm{Na}^{+}, \mathrm{Zn}^{2+}$ etc. can also be a part of the crystal structure of HAP through ion-substitutions [1-3].

Due to its physico-chemical similarity to the calcium phosphate based materials in natural hard tissues, synthetic HAP has attracted considerable interest in the past few decades. It possesses outstanding biocompatibility, non-toxicity and osteoconductivity which characteristics make it a potential material for orthopedic, dental and other biomedical applications. It can be used as implants or as coating on implants since it is able to form chemical bonds with living tissue [4,5]. Furthermore, synthetic HAPs have promising applications in drug carrying, protein delivery, growth factor transporter in vitro dissolution, apatite forming ability, antibacterial activity or in vitro cytotoxicity [6-11].

Numerous studies demonstrated the significance and benefits of ion-substitutions in the crystal structure of synthetic HAP. Both cationic $\left(\mathrm{Ag}^{+}, \mathrm{Mg}^{2+}, \mathrm{Sr}^{2+}, \mathrm{Zn}^{2+},\right)$ and anionic $\left(\mathrm{CO}_{3}{ }^{2-}, \mathrm{F}^{-}\right.$, silicate) substituents can be incorporated to some degree into HAP to replace the calcium or phosphate and hydroxyl groups, respectively. These ion incorporations produce modifications in many physical properties due to the different ionic radii, such as crystallinity, crystallite size, lattice parameters, morphology or even in thermal stability 
and solubility [2,12-17]. Additionally, these substitutions can develop or enhance certain characteristics of HAP which improve its biological response and make it more favorable for medical applications. E.g. $\mathrm{Ag}^{+}$-substitution results unique antibacterial activity and makes it suitable for bone repair based on in vitro studies [13,17-20]. Besides $\mathrm{Ag}^{+}$, other ions, such as $\mathrm{Mg}^{2+}, \mathrm{Sr}^{2+}$ and $\mathrm{Zn}^{2+}$-incorporations also evolve the antibacterial activity of the substituted HAPs [21-23]. Furthermore, with Mg- or Sr-substitutions the biocompatibility and osteoconductivity of HAP can be also improved $[2,13,14,17,22]$.

In this study, we prepared pure, Sr- and Mg-substituted HAP samples by precipitation method, using molar ratio 1.67 for $\mathrm{Ca} / \mathrm{P},(\mathrm{Ca}+\mathrm{Sr}) / \mathrm{P}$ and $(\mathrm{Ca}+\mathrm{Mg}) / \mathrm{P}$ in accordance with the HAP stoichiometry. After all the preparations, we conducted a $900{ }^{\circ} \mathrm{C}$ annealing to improve the crystallinity of the samples. The reaction products were analyzed by XRD, SEM and EDX. Since the effective ion incorporation generates changes in the crystal structure due to the different ionic radii, we determined the lattice parameters and crystallite sizes of the products. As the ionic radius of $\mathrm{Ca}^{2+}$ is $0.99 \AA$, but it is $1.12 \AA$ for $\mathrm{Sr}^{2+}$ and $0.72 \AA$ for $\mathrm{Mg}^{2+}$, enlargement or shrinkage of unit cell, respectively, is expectable.

Finally, we tested the antibacterial activity of the pure and substituted HAPs by microdilution and tetrazolium reduction assay.

\section{Experimental}

\subsection{Preparation of pure and Sr-doped HAP}

The synthesis of pure and Sr-doped HAP was carried out by the precipitation method. 0.3 M calcium nitrate tetrahydrate $\left[\mathrm{Ca}\left(\mathrm{NO}_{3}\right)_{2} \cdot 4 \mathrm{H}_{2} \mathrm{O}\right.$, Sigma Aldrich] solution $(\mathbf{A})$ and $0.29 \mathrm{M}$ 
diammonium hydrogen phosphate $\left[\left(\mathrm{NH}_{4}\right)_{2} \mathrm{HPO}_{4}\right.$, Sigma Aldrich] solution (B) were prepared separately in such an amount to keep the molar ratio of $\mathrm{Ca} / \mathrm{P}$ or $(\mathrm{Ca}+\mathrm{Sr} / \mathrm{P}$ at 1.67

(Table 1). When producing Sr-doped HAP, $\mathrm{Sr}\left(\mathrm{NO}_{3}\right)_{2}$ (Sigma Aldrich) as $\mathrm{Sr}$ source was used together with $\mathrm{Ca}\left(\mathrm{NO}_{3}\right)_{2}$ for A. Subsequently, B was added dropwise to $\mathbf{A}$ under constant stirring, and white precipitate formed immediately. Then the $\mathrm{pH}$ was set by $\mathrm{NH}_{4} \mathrm{OH}(25 \%)$ to 11 and the whole mixture was stirred for 24 hours at room temperature. Finally, the precipitate was collected by filtering, washed with ion-exchanged water and dried at $80{ }^{\circ} \mathrm{C}$ for 12 hours.

For investigating the effect of calcination we calcined the samples for $1 \mathrm{~h}$ at $900{ }^{\circ} \mathrm{C}$.

The performed experiments are summarized in Table 1. First, we studied the effect of calcination at $900{ }^{\circ} \mathrm{C}$ for $1 \mathrm{~h}$. After that we carried out Sr-doping with 2, 4, 6, 8 and 12 mol\% (SrHAP2, SrHAP4, SrHAP6, SrHAP8, and SrHAP12, respectively). HAPrt means at room temperature-prepared HAP while HAPht means annealed HAP at $900{ }^{\circ} \mathrm{C}$.

\subsection{Preparation of pure and Mg-doped HAP}

$\mathrm{Ca}\left(\mathrm{NO}_{3}\right)_{2} \cdot 4 \mathrm{H}_{2} \mathrm{O}(\mathbf{C})$ and $\left(\mathrm{NH}_{4}\right)_{2} \mathrm{HPO}_{4}(\mathbf{D})$ solutions were made with the concentration of $0.3 \mathrm{M}$ and $0.29 \mathrm{M}$, respectively. The $\mathrm{Mg}$ source was magnesium nitrate $\left[\mathrm{Mg}\left(\mathrm{NO}_{3}\right)_{2} \cdot 6\right.$ $\mathrm{H}_{2} \mathrm{O}$, Sigma Aldrich], which was applied beside $\mathrm{Ca}\left(\mathrm{NO}_{3}\right)_{2}$ in $\mathbf{C}$. In every case the molar ratio of $\mathrm{Ca} / \mathrm{P}$ or $(\mathrm{Ca}+\mathrm{Mg}) / \mathrm{P}$ was 1.67 (Table 2). After that, $\mathbf{D}$ was added gradually to $\mathbf{C}$, which was followed by formation of white precipitate. Subsequently, the mixed solution was stirred for $5 \mathrm{~h}$ at $90{ }^{\circ} \mathrm{C}$ and then left for aging for 3 days. Finally, it was filtered, washed with ion-exchanged water and dried at $120^{\circ} \mathrm{C}$ for $12 \mathrm{~h}$, and calcined at $900{ }^{\circ} \mathrm{C}$ for $2 \mathrm{~h}$. 
All details of the conducted experiments are in Table 2. First, pure HAP was synthetized (HAP90) and then Mg-doped HAP with 2 and $4 \mathrm{~mol} \%$ of $\mathrm{Mg} /(\mathrm{Ca}+\mathrm{Mg})(\mathrm{MgHAP} 2$, MgHAP4).

HAP90 means the pure HAP prepared applying $90{ }^{\circ} \mathrm{C}$ strring and 3 days aging.

\subsection{Characterization}

XRD measurements were carried out by a PANanalytical X'Pert Pro MPD diffractometer with $\mathrm{Cu} \mathrm{K} \alpha$ radiation $(\lambda=0.15418 \mathrm{~nm})$. To demonstrate the ion incorporation, we carried out lattice parameter calculation using HighScore Plus powder diffraction software. The statistically significant difference between the lattice parameters of pure and doped HAPs was proved by $\mathrm{F}$ t-test. Crystallite sizes of the products was evaluated based on the XRD

patterns using the Scherrer-formula: $D=\frac{k \lambda}{\beta_{m} \cos \theta}$, where $D(\AA)$ is the crystallite size, $k$ is a unitless form factor (0.9), $\lambda$ is the wavelength used of the $\mathrm{X}$-ray source (1.5418 $\AA$ ), $\beta$ is the physical broadening of the line (full width at half maximum), and $\theta$ (rad) is the diffraction angle. The (002) and (310) HA reflections were chosen for the analysis of line broadening along the c-axis and along a direction perpendicular to it, respectively. For investigating the morphology of the obtained materials a LEO $1540 \mathrm{XB}$ electron microscope while for EDX measurements a JEOL JSM 5500-LV instrument was applied.

\subsection{Antibacterial activity and in vitro cytotoxicity testing}

The antibacterial activity and in vitro cytotoxicity of pure and Sr-, Mg-doped HAP samples were determined by microdilution method and tetrazolium reduction assay.

Antibacterial tests were carried out against two Gram-negative (Escherichia coli ATCC 25922 (American Type Culture Collection) and Klebsiella pneumoniae ATCC 49619) 
and three Gram-positive bacteria species (Enterococcus faecalis ATCC 29212, Staphylococcus aureus ATCC 25923, S. epidermidis ATCC 29212). The bacteria were prepared in MH (Mueller-Hinton; VWR) broth and were incubated at $37^{\circ} \mathrm{C}$ overnight. The assays were performed in 96-well microtiter plates, using a two-fold serial dilution of the HAP samples starting from $200 \mu \mathrm{g} / \mathrm{ml} .10^{-4}$ dilution of an overnight bacterial culture in $100 \mu \mathrm{L}$ of $\mathrm{MH}$ were then added to each well with the exception of the medium control wells. Then, the plates were incubated at $37{ }^{\circ} \mathrm{C}$ for $18 \mathrm{~h}$ and at the end of the incubation period the MIC values of tested compounds were determined by naked eyes.

In order to investigate whether the different types of pure and substituted HAPs affect the cell viability, the tetrazolium reduction assay was applied using 2-(p-iodophenyl)-3(pnitrophenyl)-5-phenyl tetrazolium chloride (INT). In the presence of bacteria, the tetrazolium salt (INT) is reduced to red formazan, which is directly proportional to the viable active cells.

The antibacterial activity test on Escherichia coli ATCC 25922 was carried out by direct contact method in shaken tubes with $10 \mathrm{~mL}$ of volume Luria-Bertani Broth inoculated with $100-100 \mu \mathrm{L}$ overnight $E$. coli suspension. The antimicrobial activity of HAP samples was determined at $500 \mu \mathrm{g} / \mathrm{mL}$ and $1500 \mu \mathrm{g} / \mathrm{mL}$ concentrations in 3-3 parallels after 24 and $48 \mathrm{~h}$ incubation time. Control samples without HAPs were also applied in 5 parallels. After 24 and 48 h contact time $200-200 \mu \mathrm{L}$ of sample was taken out from each tubes and pipetted into 96-well microtiter plate. The optical density (OD) was registered and quantity of formazan was measured after addition of $30 \mu \mathrm{L}$ sterile INT solution to each cells by recording changes in absorbance at $490 \mathrm{~nm}$ using a DIALAB ELx800 ELISA microplate reader. One-way analysis of variance (ANOVA) was performed by STATISTICA $13.1 \circledR$ software identifying significant effects $(\mathrm{p}<0.05)$. 


\section{Results and discussion}

\subsection{XRD}

\subsubsection{Effect of calcination}

For investigating the role of calcination we applied a $1 \mathrm{~h}$ treatment at $900{ }^{\circ} \mathrm{C}$ after the precipitation procedure using the undoped sample. HAPrt prepared without calcination and HAPht calcined at $900{ }^{\circ} \mathrm{C}$ were both composed of pure HAP (ICDD: 04-016-1647) but with different crystallinity (Fig. 1). HAPht has much sharper and narrower peaks, which refers to that HAPht has a more considerably crystallized structure due to the calcination at $900{ }^{\circ} \mathrm{C}$. Since this annealing step does not change the crystalline phase of the prepared samples but improves their crystallinity, at every further preparation it was employed.

\subsubsection{Sr-doped HAPs}

Sr-doping of HAP was carried out with different $\mathrm{Sr} /(\mathrm{Ca}+\mathrm{Sr})$ molar ratios. SrHAP2, SrHAP4 were indicated as pure HAP (ICDD: 04-016-1647) without any new peaks referring to the Sr-content (Fig.2). The peak positions of SrHAP2 and SrHAP4 slightly shifted towards lower diffraction angles from $31.8482 \theta$ (HAPht) to $31.7842 \theta$ and 31.705 $2 \theta$, respectively, in the case of the most intensive peak (310). Based on the results, it was assumed that $\mathrm{Sr}$ ions incorporated into the unit cell of HAP substituting Ca ions. In the case of SrHAP6, SrHAP8 and SrHAP12 Sr-containing tricalcium phosphate $\left(\mathrm{Sr}_{0.13} \mathrm{Ca}_{2.87}\left(\mathrm{PO}_{4}\right)_{2}\right.$, ICDD: 04-015-9751) and calcium pyrophosphate $\left(\mathrm{Ca}_{2} \mathrm{P}_{2} \mathrm{O}_{7}, \mathrm{ICDD}\right.$ : 04-009-3876) phases were determined. The lack of HAP is due to the distortion effect of Sr on the phosphate environment, which promotes the decomposition of HAP at high 
temperatures $[24,25]$ and the transformation of HAP to $\beta$-TCP (tricalcium phosphate) above $700{ }^{\circ} \mathrm{C} .[26,27]$

The HAPht results are in good agreement with the ones in the reference pattern (ICDD: 01-082-2956), which are $a, b(\AA)=9.4154, c(\AA): 6.8792$ and $\mathrm{V}\left(\AA^{3}\right)=528.14$. The calculated lattice parameters obtained from the XRD patterns for the pure and Sr-doped HAPs (HAPht-SrHAP2-SrHAP4) altered slightly due to the larger ionic radius of $\mathrm{Sr}^{2+}$ (1.12 $\AA$ ) compared to $\mathrm{Ca}^{2+}(0.99 \AA$, Table 3). Paramters $a$ and $b$ changed from 9.4100 to 9.4266 $\AA, c$ from 6.8753 to $6.8925 \AA$, while the volume of unit cell expanded from 527.22 to $530.41 \AA^{3}$. In the case of the doped samples (SrHAP2 and SrHAP4) it is clearly seen that all the parameters $(a, b, c)$ and volume of the unit cell increased. This effect is attributed to the Sr incorporation into the structure of HAP which substitutes Ca ions and thus expands the unit cell. In the terms of the crystallite sizes calculated by the Scherrerformula, a significant increase is present. The FWHM values used for the calculation decreased meaning the growth of the crystallite size, which can occur to some $\mathrm{Sr}$ content $[28,29]$. The lattice parameters of SrHAP2 and SrHAP4 differed significantly compared to pure HAP based on statistical calculation ( $\mathrm{F}$ and $\mathrm{t}$ probes).

\subsubsection{Mg-doped HAPs}

Based on the XRD patterns, HAP90 and MgHAP2 were identified as pure HAP (ICDD: 04-016-1647) and no other Mg-containing phase obtained (Fig.3). The peaks were supposed to be at higher diffraction angles indicating the shrinkage of unit cell, however, the positions for the most intensive peak were $31.7762 \theta$ and $31.7612 \theta$ in HAP90 and MgHAP2, respectively. When applying $4 \% \mathrm{Mg}, \mathrm{Mg}$ and $\mathrm{Ca}$-containing phase of triphosphate was also identified (Ca2.71 $\mathrm{Mg}_{0.29}\left(\mathrm{PO}_{4}\right)_{2}$, ICDD: 04-010-2972). The results 
show that starting from $4 \%$ concentration $\mathrm{Mg}$ was not able to build into the crystal structure of HAP owing to the destabilizing influence of Mg. [30,31]

Table 4 shows the calculated lattice parameters of HAP90 and MgHAP2. The obtained values for HAP90 correspond the ones from the reference HAP pattern (ICDD: 01-0822956), which are $a, b(\AA)=9.4154, c(\AA): 6.8792$ and $\mathrm{V}\left(\AA^{3}\right)=528.14$. We expected a slight decrease in the values as the ionic radius of $\mathrm{Mg}^{2+}$ is smaller $(0.72 \AA)$ than $\mathrm{Ca}^{2+}$ $(0.99 \AA)$. Parameter $a$ and $b$ were $9.4137 \AA$ and $9.4124 \AA$ for HAP90 and MgHAP2, respectively. Even the volume of unit cell decreased from $527.73 \AA^{3}$ to $527.63 \AA^{3}$. However, parameter $c$ was $6.8764 \AA$ for HAP90 and $6.8771 \AA$ for MgHAP2, which means some distortion of the unit cell. The crystallite sizes got larger in the presence of $2 \% \mathrm{Mg}$, which was obvious due to the narrower FWHM values used for the calculation. The difference between $a, b$ lattice parameters of MgHAP2 was significant compared to HAP90 based on statistical calculation ( $\mathrm{F}$ and $\mathrm{t}$ probes).

\subsection{EDX}

Our main purpose with the EDX was to directly detect the presence of the doping ions. The lattice parameter calculations revealed changes in the unit cells referring to the incorporation but the ions are expected to be detected by EDX as well.

\subsubsection{Sr-doped HAPs}

$\mathrm{Ca}, \mathrm{Sr}, \mathrm{P}$ and $\mathrm{O}$ elements were the main components in each sample. This indicates that the washing process after filtering was sufficient as $\mathrm{N}$ was not observed during the measurements. Table 5 presents that the $\mathrm{Ca} / \mathrm{P}$ or $(\mathrm{Ca}+\mathrm{Sr}) / \mathrm{P}$ molar ratios are approximately 1.67 in the case of HAPht and SrHAP4 but only 1.42 for SrHAP2. This small ratio would mean the formation of Ca-deficient HAP which decomposes above 700 
${ }^{\circ} \mathrm{C}$ to $\beta$-TCP $[26,27,32]$. As the samples were pure HAP without any other phases, we assume the real value is close to the theoretical 1.67. For the same reason, the discrepancies in $\mathrm{Sr} /(\mathrm{Ca}+\mathrm{Sr})$ ratios (1.71 for SrHAP2, 2.71 for SrHAP4) is attributed to the non-accuracy of EDX for quantitative analysis. In the case of SrHAP6, SrHAP8 and SrHAP12 the decrease of measured $\mathrm{Sr} \%$ is according to the formation of new phases $\left(\mathrm{Sr}_{\mathrm{x}} \mathrm{Ca}_{3-\mathrm{x}}\left(\mathrm{PO}_{4}\right)_{2}, \mathrm{Ca}_{2} \mathrm{P}_{2} \mathrm{O}_{7}\right.$, Table 5, Fig.S1).

\subsubsection{Mg-doped HAPs}

HAP90, MgHAP2 and MgHAP4 consisted of only Ca, Mg, P and O (Table 6, Fig. S2). $\mathrm{N}$ was not detectable, which is in good agreement with the XRD results, where pure HAP (HAP90, MgHAP2) and $\mathrm{Mg}_{0.29} \mathrm{Ca}_{2.71}\left(\mathrm{PO}_{4}\right)_{2}$ (MgHAP4) were identified. We conclude that the $\mathrm{Ca} / \mathrm{P}$ and $(\mathrm{Ca}+\mathrm{Mg}) / \mathrm{P}$ atomic ratios were 1.67 at each sample, since according to the XRD results $\mathrm{MgHAP} 2$ has composed of only HAP. The measured $\mathrm{Mg} /(\mathrm{Ca}+\mathrm{Mg})$ ratios is considered closing the planned 2 and $4 \%$. In the case of MgHAP4 the difference is attributed to formation not only HAP but a new phase.

\subsection{Morphology}

In the SEM image of HAPht nanometer sized grains are observable, which are highly sintered (Fig.4). In the case of SrHAP2 and SrHAP4 formation of elongated shapes, similar to HAPht, can be seen. The sintered forms have dimensions of 100-200 nm and are strongly stacked to each other. According to them, the incorporation of Sr-ion into the crystal structure of HAP does not change the morphology significantly.

In the case of SrHAP6, SrHAP8, SrHAP12 the samples were composed of larger crystals with various shapes and sizes (more than $500 \mathrm{~nm}$, Fig.4). This effect is due to the fact 
that in these experiments not HAP but other phases $\left(\mathrm{Sr}_{0.13} \mathrm{Ca}_{2.87}\left(\mathrm{PO}_{4}\right)_{2},\left(\mathrm{Ca}_{2} \mathrm{P}_{2} \mathrm{O}_{7}\right)\right)$ were formed.

In the SEM images of HAP90, MgHAP2 and MgHAP4 (Fig.5) it can be detected that the morphology of the samples are homogenous and consist of mostly some roundish forms, however, with different sizes. In the case of MgHAP2 these forms are in the range of 400$500 \mathrm{~nm}$ while in MgHAP4 they are 100-200 $\mathrm{nm}$ compared to HAP90. HAP90 is composed of mostly $300 \mathrm{~nm}$ rounded grains.

\subsection{Antibacterial activity and in vitro cytotoxicity testing}

Testing of the antibacterial activity and in vitro cytotoxicity of the pure, Sr- and Mgdoped HAP samples was carried out by determination MIC values using microdilution and INT reduction method.

Based on the results of the microdilution method, MgHAP2 had effect on inhibiting the growth of both Gram-positive and negative strains compared to pure HAP (Table 7). In the case of SrHAP2 and SrHAP4 this effect can occur at more than $200 \mu \mathrm{g} / \mathrm{ml}$ concentrations.

According to the results of INT reduction, SrHAP4 was effective against $E$. coli as the absorbance was decreased at both applied concentration. Statistically significant decrease ( $26 \%$ inhibition) was observed at $1500 \mu \mathrm{g} / \mathrm{ml}$ SrHAP4. Slight but not significant antibacterial activity ( $10 \%$ inhibition) was found in the case of MgHAP2 compared to control (Fig. 6).

\section{Conclusion}


In this study we synthetized pure HAP by precipitation method and incorporated $\mathrm{Sr}$ and Mg-ions into its crystal lattice. We applied different molar ratios: 2, 4, 6, 8 and 12 $\mathrm{Sr} /(\mathrm{Ca}+\mathrm{Sr}) \mathrm{mol} \%$ and $2,4 \mathrm{Mg} /(\mathrm{Ca}+\mathrm{Mg})$ mol\%. Based on the XRD measurements we found that SrHAP2 and SrHAP4 had pure crystalline HAP structure and the EDX experiments definitely showed Sr content. The same happened at in MgHAP2 which was identified pure HAP and EDX detected Mg presence. The other samples, prepared with different molar ratios of $\mathrm{Sr}$ and $\mathrm{Mg}$, consisted of $\mathrm{Sr}_{0.13} \mathrm{Ca}_{2.87}\left(\mathrm{PO}_{4}\right)_{2}, \mathrm{Ca}_{2} \mathrm{P}_{2} \mathrm{O}_{7}$, $\mathrm{Mg}_{0.29} \mathrm{Ca}_{2.71}\left(\mathrm{PO}_{4}\right)_{2}$. The ion incorporation into the crystalline hexagonal structure of HAP induced changes in the parameters and volume of the unit cell, moreover in the crystallite size. Since the bigger ionic radius of $\mathrm{Sr}^{2+}$ to $\mathrm{Ca}^{2+}$ in SrHAP2 and SrHAP4 the unit cell of HAP expanded confirmed by the increasing of parameter $a(b), c$ and the volume of unit cell. As the ionic radius of $\mathrm{Mg}^{2+}$ is smaller than $\mathrm{Ca}^{2+}$, we demonstrated that $a(b)$ parameters and unit cell volume decreased. Parameter $c$ was however increased, which refers unit cell distortion. Crystallite sizes increased when the amount of $\mathrm{Sr}$ and $\mathrm{Mg}$ was higher as a consequence of the narrower XRD reflections compared to the pure HAPs. SEM images showed that every sample had homogenous morphology, with elongated and roundish shapes strongly stacked to each other. These forms were 100-200 nm wide in the case of 2 and $4 \% \mathrm{Sr}$ but at higher amounts of Sr they were larger (400-500 nm). 2 $\% \mathrm{Mg}$ HAP resulted larger roundish crystals than in the case of $4 \% \mathrm{Mg}$. Results of antimicrobial experiments showed that in the case of MgHAP2 sample the MIC value was $100 \mu \mathrm{g} / \mathrm{ml}$, however, more than $200 \mu \mathrm{g} / \mathrm{ml}$ for the Sr-doped HAPs on the tested strains. For in vitro cytotoxicity tests only SrHAP4 had influence on the reduction of INT compared to the pure sample at $1500 \mu \mathrm{g} / \mathrm{ml}, \mathrm{MgHAP} 2$ revealed slight differences.

\section{Associated content}


Supporting Information. EDX spectra of HAPht, SrHAP2, SrHAP4, SrHAP6, SrHAP8 and SrHAP12 (Fig.S1) and EDX spectra of HAP90, MgHAP2 and MgHAP4 (Fig.S2).

\section{Acknowledgements}

T. Nagyné-Kovács thanks for an ÚNKP-17-3-I-BME-192 grant supported by the ÚNKP17-3-I New National Excellence Program of the Ministry of Human Capacities, Hungary. I. M. Szilágyi thanks for a János Bolyai Research Fellowship of the Hungarian Academy of Sciences and an ÚNKP-17-4-IV-BME-188 grant supported by the ÚNKP-17-4-IV New National Excellence Program of the Ministry of Human Capacities, Hungary. An NRDI K 124212 and an NRDI TNN_16 123631 grant are acknowledged. The research within project No. VEKOP-2.3.2-16-2017-00013 was supported by the European Union and the State of Hungary, co-financed by the European Regional Development Fund. The research reported in this paper was supported by the Higher Education Excellence Program of the Ministry of Human Capacities in the frame of Nanotechnology and Materials Science research area of Budapest University of Technology (BME FIKPNAT). 


\section{References}

[1] C. Combes, S. Cazalbou, C. Rey, Apatite Biominerals, Minerals. 6 (2016) 34. doi:10.3390/min6020034.

[2] J.T.B. Ratnayake, M. Mucalo, G.J. Dias, Substituted hydroxyapatites for bone regeneration: A review of current trends, J. Biomed. Mater. Res. - Part B Appl. Biomater. 105 (2017) 1285-1299. doi:10.1002/jbm.b.33651.

[3] P.. Downey, M. Siegel, Bone Biology and the Clinical Implications for osteoporosis, Phys. Ther. 86 (2006) 77-91.

[4] T. Inadome, K. Hayashi, Y. Nakashima, H. Tsumura, Y. Sugioka, Comparison of bone implant interface shear strength of hydroxyapatite-coated and alumina-coated metal implants, J. Biomed. Mater. Res. 29 (1995) 19-24. doi:10.1002/jbm.820290104.

[5] K. Søballe, E.S. Hansen, H. B.-Rasmussen, P.H. Jørgensen, C. Bünger, Tissue ingrowth into titanium and hydroxyapatite-coated implants during stable and unstable mechanical conditions, J. Orthop. Res. 10 (1992) 285-299. doi:10.1002/jor.1100100216.

[6] M. Okada, T. Furuzono, Hydroxylapatite nanoparticles: Fabrication methods and medical applications, Sci. Technol. Adv. Mater. 13 (2012). doi:10.1088/14686996/13/6/064103.

[7] C. Shi, J. Gao, M. Wang, J. Fu, D. Wang, Y. Zhu, Ultra-trace silver-doped hydroxyapatite with non-cytotoxicity and effective antibacterial activity, Mater. Sci. Eng. C. 55 (2015) 497-505. doi:10.1016/j.msec.2015.05.078.

[8] N. Ohtsu, Y. Kakuchi, T. Ohtsuki, Antibacterial effect of zinc oxide/hydroxyapatite coatings prepared by chemical solution deposition, Appl. Surf. Sci. (2017). doi:10.1016/j.apsusc.2017.09.101.

[9] G.S. Kumar, A. Thamizhavel, Y. Yokogawa, S.N. Kalkura, E.K. Girija, Synthesis, 
characterization and in vitro studies of zinc and carbonate co-substituted nanohydroxyapatite for biomedical applications, Mater. Chem. Phys. 134 (2012) 1127-1135. doi:10.1016/j.matchemphys.2012.04.005.

[10] K. Lin, P. Liu, L. Wei, Z. Zou, W. Zhang, Y. Qian, Y. Shen, J. Chang, Strontium substituted hydroxyapatite porous microspheres: Surfactant-free hydrothermal synthesis, enhanced biological response and sustained drug release, Chem. Eng. J. 222 (2013) 4959. doi:10.1016/j.cej.2013.02.037.

[11] D. Gopi, E. Shinyjoy, L. Kavitha, Synthesis and spectral characterization of silver/magnesium co-substituted hydroxyapatite for biomedical applications, Spectrochim. Acta - Part A Mol. Biomol. Spectrosc. 127 (2014) 286-291. doi:10.1016/j.saa.2014.02.057.

[12] F. Miyaji, Y. Kono, Y. Suyama, Formation and structure of zinc-substituted calcium hydroxyapatite, Mater. Res. Bull. 40 (2005) 209-220. doi:10.1016/j.materresbull.2004.10.020.

[13] K.T. Arul, J.R. Ramya, G.M. Bhalerao, S.N. Kalkura, Physicochemical characterization of the superhydrophilic, magnesium and silver ions co-incorporated nanocrystalline hydroxyapatite, synthesized by microwave processing, Ceram. Int. 40 (2014) 1377113779. doi:10.1016/j.ceramint.2014.05.088.

[14] A. Bigi, E. Boanini, C. Capuccini, M. Gazzano, Strontium-substituted hydroxyapatite nanocrystals, Inorganica Chim. Acta. 360 (2007) 1009-1016. doi:10.1016/j.ica.2006.07.074.

[15] N. Lowry, Y. Han, B.J. Meenan, A.R. Boyd, Strontium and zinc co-substituted nanophase hydroxyapatite, Ceram. Int. 43 (2017) 12070-12078. doi:10.1016/j.ceramint.2017.06.062. 
[16] N. Patel, S.M. Best, W. Bonfield, I.R. Gibson, K.A. Hing, E. Damien, P.A. Revell, A comparative study on the in vivo behavior of hydroxyapatite and silicon substituted hydroxyapatite granules, J. Mater. Sci. Mater. Med. 13 (2002) 1199-1206. doi:10.1023/A:1021114710076.

[17] J.H. Shepherd, D. V. Shepherd, S.M. Best, Substituted hydroxyapatites for bone repair, J. Mater. Sci. Mater. Med. 23 (2012) 2335-2347. doi:10.1007/s10856-012-4598-2.

[18] P.N. Lim, E.Y. Teo, B. Ho, B.Y. Tay, E.S. Thian, Effect of silver content on the antibacterial and bioactive properties of silver-substituted hydroxyapatite, J. Biomed. Mater. Res. - Part A. 101 A (2013) 2456-2464. doi:10.1002/jbm.a.34544.

[19] T.N. Kim, Q.L. Feng, J.O. Kim, J. Wu, H. Wang, G.C. Chen, F.Z. Cui, Antimicrobial effects of metal ions $(\mathrm{Ag}+, \mathrm{Cu} 2+, \mathrm{Zn} 2+)$ in hydroxyapatite, J. Mater. Sci. Mater. Med. 9 (1998) 129-134. doi:10.1023/A:1008811501734.

[20] A. Ewald, D. Hösel, S. Patel, L.M. Grover, J.E. Barralet, U. Gbureck, Silver-doped calcium phosphate cements with antimicrobial activity, Acta Biomater. 7 (2011) 4064 4070. doi:10.1016/j.actbio.2011.06.049.

[21] A. Farzadi, F. Bakhshi, M. Solati-Hashjin, M. Asadi-Eydivand, N.A.A. Osman, Magnesium incorporated hydroxyapatite: Synthesis and structural properties characterization, Ceram. Int. 40 (2014) 6021-6029. doi:10.1016/j.ceramint.2013.11.051.

[22] N.D. Ravi, R. Balu, T.S. Sampath Kumar, Strontium-substituted calcium deficient hydroxyapatite nanoparticles: Synthesis, characterization, and antibacterial properties, J. Am. Ceram. Soc. 95 (2012) 2700-2708. doi:10.1111/j.1551-2916.2012.05262.x.

[23] V. Stanić, S. Dimitrijević, J. Antić-Stanković, M. Mitrić, B. Jokić, I.B. Plećaš, S. Raičević, Synthesis, characterization and antimicrobial activity of copper and zinc-doped hydroxyapatite nanopowders, Appl. Surf. Sci. 256 (2010) 6083-6089. 
doi:10.1016/j.apsusc.2010.03.124.

[24] Z.Y. Li, W.M. Lam, C. Yang, B. Xu, G.X. Ni, S.A. Abbah, K.M.C. Cheung, K.D.K. Luk, W.W. Lu, Chemical composition, crystal size and lattice structural changes after incorporation of strontium into biomimetic apatite, Biomaterials. 28 (2007) 1452-1460. doi:10.1016/j.biomaterials.2006.11.001.

[25] H.W. Kim, Y.H. Koh, Y.M. Kong, J.G. Kang, H.E. Kim, Strontium substituted calcium phosphate biphasic ceramics obtained by a powder precipitation method, J. Mater. Sci. Mater. Med. 15 (2004) 1129-1134. doi:10.1023/B:JMSM.0000046395.76435.60.

[26] I.R. Gibson, I. Rehman, S.M. Best, W. Bonfield, Characterization of the transformation from calcium-deficient apatite to $\beta$-tricalcium phosphate, J. Mater. Sci. Mater. Med. 11 (2000) 799-804. doi:10.1023/A:1008905613182.

[27] D. dos S. Tavares, C.X. Resende, M.P. Quitan, L. de O. Castro, J.M. Granjeiro, G. de A. Soares, Incorporation of strontium up to $5 \mathrm{Mol} .(\%)$ to hydroxyapatite did not affect its cytocompatibility, Mater. Res. 14 (2011) 456-460. doi:10.1590/S151614392011005000073.

[28] P.H. RABELO NETO, J. S.; KNOPF, T. B.; FREDEL, M. C.; OLATE, S. \& DE MORAES, Synthesis and Characterization of Calcium Phosphate Compounds with Strontium and Magnesium Ionic Substitutions, Int. J. Morphol. 33 (2015) 1189-1193. doi:10.4067/S0717-95022015000300061.

[29] R. V Suganthi, K. Elayaraja, M.I.A. Joshy, V.S. Chandra, E.K. Girija, S.N. Kalkura, Fibrous growth of strontium substituted hydroxyapatite and its drug release, Mater. Sci. Eng. C. 31 (2011) 593-599. doi:10.1016/j.msec.2010.11.025.

[30] A. Bigi, G. Falini, E. Foresti, A. Ripamonti, M. Gazzano, N. Roveri, Magnesium influence on hydroxyapatite crystallization, J. Inorg. Biochem. 49 (1993) 69-78. 
doi:10.1016/0162-0134(93)80049-F.

[31] F. Ren, Y. Leng, R. Xin, X. Ge, Synthesis, characterization and ab initio simulation of magnesium-substituted hydroxyapatite, Acta Biomater. 6 (2010) 2787-2796. doi:10.1016/j.actbio.2009.12.044.

[32] L. Leroux, J.L. Lacout, Preparation of calcium strontium hydroxyapatites by a new route involving calcium phosphate cements, J. Mater. Res. 16 (2001) 171-178. doi:10.1557/JMR.2001.0028. 


\section{Table and figure captions}

Table 1 Details of the preparation of pure and Sr-doped HAP

Table 2 Details of the preparation of pure and Mg-doped HAP

Table 3 Calculated lattice parameters of HAPht, SrHAP2 and SrHAP4

Table 4 Calculated lattice parameters of HAP90 and MgHAP2

Table 5 EDX results of pure and Sr-doped HAPs

Table 6 EDX results of pure and Mg-doped HAPs

Table 7 Results of MIC determination by microdilution method

Figure 1 XRD patterns of HAPrt and HAPht

Figure 2 XRD patterns of pure and Sr-doped HAPs

Figure 3 XRD patterns of pure and Mg-doped HAPs

Figure 4 SEM images of pure and Sr-doped HAPs

Figure 5 SEM images of pure and Mg-doped HAPs

Figure 6 Tetrazolium (INT) reduction results for pure and doped HAP samples 
Table 7

HAPrt HAPht SrHAP2 SrHAP4 SrHAP6 SrHAP8 SrHAP12

\begin{tabular}{|c|c|c|c|c|c|c|c|}
\hline $\mathrm{Sr} /(\mathrm{Ca}+\mathrm{Sr})[\mathrm{mol} \%]$ & 0 & 0 & 2 & 4 & 6 & 8 & 12 \\
\hline$(\mathrm{Sr}+\mathrm{Ca}) / \mathrm{P}$ & 1.67 & 1.67 & 1.67 & 1.67 & 1.67 & 1.67 & 1.67 \\
\hline $\begin{array}{c}\mathrm{Ca}\left(\mathrm{NO}_{3}\right)_{2} \cdot 4 \mathrm{H}_{2} \mathrm{O} \\
(\mathrm{mol})\end{array}$ & 0.02030 & 0.02030 & 0.01994 & 0.01953 & 0.01912 & 0.01871 & 0.01790 \\
\hline $\mathrm{Sr}\left(\mathrm{NO}_{3}\right)_{2}(\mathrm{mmol})$ & 0 & 0 & 0.407 & 0.814 & 1.220 & 1.627 & 2.440 \\
\hline $\mathbf{c}_{\mathrm{A}}(\mathbf{M})$ & 0.30 & 0.30 & 0.30 & 0.30 & 0.30 & 0.30 & 0.30 \\
\hline$\left(\mathrm{NH}_{4}\right)_{2} \mathrm{HPO}_{4}(\mathrm{~mol})$ & 0.012 & 0.012 & 0.012 & 0.012 & 0.012 & 0.012 & 0.012 \\
\hline св (M) & 0.29 & 0.29 & 0.29 & 0.29 & 0.29 & 0.29 & 0.29 \\
\hline Calcination $\left(900^{\circ} \mathrm{C}\right)$ & no & yes & yes & yes & yes & yes & yes \\
\hline
\end{tabular}


Table 8

\section{HAP90 MgHAP2 MgHAP4}

\begin{tabular}{cccc}
\hline $\mathbf{M g} /(\mathbf{C a}+\mathbf{M g})[\mathrm{mol} \%]$ & 0 & 2 & 4 \\
$(\mathbf{M g}+\mathbf{C a}) / \mathbf{P}$ & 1.67 & 1.67 & 1.67 \\
$\mathbf{C a}\left(\mathbf{N O}_{3}\right)_{2} \cdot \mathbf{4 H} \mathbf{H}_{2} \mathbf{O}(\mathrm{mol})$ & 0.02 & 0.0196 & 0.0192 \\
$\mathbf{M g}\left(\mathbf{N O}_{3}\right)_{2} \cdot 6 \mathbf{H}_{2} \mathbf{O}(\mathrm{mmol})$ & 0 & 0.4 & 0.8 \\
$\mathbf{c C}(\mathrm{M})$ & 0.2 & 0.2 & 0.2 \\
$\left(\mathbf{N H}_{4}\right)_{2} \mathbf{H P O}_{4}(\mathrm{~mol})$ & 0.012 & 0.012 & 0.012 \\
$\mathbf{c}_{\mathbf{D}}(\mathrm{M})$ & 0.12 & 0.12 & 0.12 \\
$\left.\mathbf{C a l c i n a t i o n}^{(900}{ }^{\circ} \mathbf{C}\right)$ & yes & yes & yes
\end{tabular}


Table 9

\begin{tabular}{ccccccc} 
& \multicolumn{3}{c}{ Lattice parameters } & \multicolumn{3}{c}{ Crystallite size (nm) } \\
& $\mathrm{a}(\AA)$ & $\mathrm{b}(\AA)$ & $\mathrm{c}(\AA)$ & $\mathrm{V}\left(\AA^{3}\right)$ & 002 & 310 \\
\hline HAPht & 9.4100 & 9.4100 & 6.8753 & 527.22 & 48.27 & 38.26 \\
SrHAP2 & 9.4189 & 9.4189 & 6.8851 & 528.99 & 70.94 & 67.11 \\
SrHAP4 & 9.4266 & 9.4266 & 6.8925 & 530.41 & 95.90 & 62.62
\end{tabular}


Table 10

\begin{tabular}{ccccccc} 
& \multicolumn{3}{c}{ Lattice parameters } & \multicolumn{3}{c}{ Crystallite size (nm) } \\
& $\mathrm{a}(\AA)$ & $\mathrm{b}(\AA)$ & $\mathrm{c}(\AA)$ & $\mathrm{V}\left(\AA^{3}\right)$ & 002 & 310 \\
\hline HAP90 & 9.4137 & 9.4137 & 6.8764 & 527.73 & 113.37 & 100.70 \\
MgHAP2 & 9.4124 & 9.4124 & 6.8771 & 527.63 & 151.22 & 176.38
\end{tabular}


Table 11

HAPht SrHAP2 SrHAP4 SrHAP6 SrHAP8 SrHAP12

\begin{tabular}{ccccccc}
\hline $\mathbf{C a}($ atom \%) & 21.48 & 14.92 & 18.34 & 16.35 & 13.89 & 24.92 \\
$\mathbf{S r}($ atom \%) & - & 0.26 & 0.51 & 0.49 & 0.78 & 0.94 \\
$\mathbf{P}($ atom \%) & 12.93 & 10.70 & 11.73 & 13.31 & 12.04 & 14.86 \\
$\mathbf{O}($ atom \%) & 65.59 & 74.13 & 69.41 & 69.85 & 73.28 & 59.28 \\
$\mathbf{C a} / \mathbf{P ~ o r ~}(\mathbf{C a}+\mathbf{S r}) / \mathbf{P}$ & 1.66 & 1.42 & 1.61 & 1.27 & 1.22 & 1.74 \\
$\mathbf{S r} / \mathbf{C a}+\mathbf{S r})$ & - & 1.71 & 2.71 & 2.91 & 5.32 & 3.63
\end{tabular}


Table 12

\begin{tabular}{cccc} 
& HAP90 & MgHAP2 & MgHAP4 \\
\hline Ca (atom \%) & 22.63 & 19.92 & 19.59 \\
Mg (atom \%) & - & 0.33 & 0.63 \\
P (atom \%) & 12.58 & 12.06 & 13.26 \\
O (atom \%) & 64.79 & 67.68 & 66.52 \\
Ca/P or $(\mathbf{C a + M g ) / P}$ & 1.80 & 1.68 & 1.52 \\
Mg/(Ca+Mg) & - & 1.63 & 3.12
\end{tabular}


Table 7

\begin{tabular}{cccccc} 
& HAPht & SrHAP2 & SrHAP4 & HAP90 & MgHAP2 \\
\hline $\begin{array}{c}\text { S. aureus } \\
\text { ATCC 25923 }\end{array}$ & $>200$ & $>200$ & $>200$ & $>200$ & 100 \\
$\begin{array}{c}\text { S. } \text { epidermidis } \\
\text { ATCC 12228 }\end{array}$ & $>200$ & $>200$ & $>200$ & $>200$ & 100 \\
$\begin{array}{c}\text { E. } \text { faecalis } \\
\text { ATCC 29212 }\end{array}$ & $>200$ & $>200$ & $>200$ & $>200$ & 100 \\
$\begin{array}{c}\text { K. pneumoniae } \\
\text { ATCC 49619 }\end{array}$ & $>200$ & $>200$ & $>200$ & $>200$ & 100 \\
$\quad$ E. coli & $>200$ & $>200$ & $>200$ & $>200$ & 100 \\
ATCC 25922 & & & & &
\end{tabular}


Figure 4

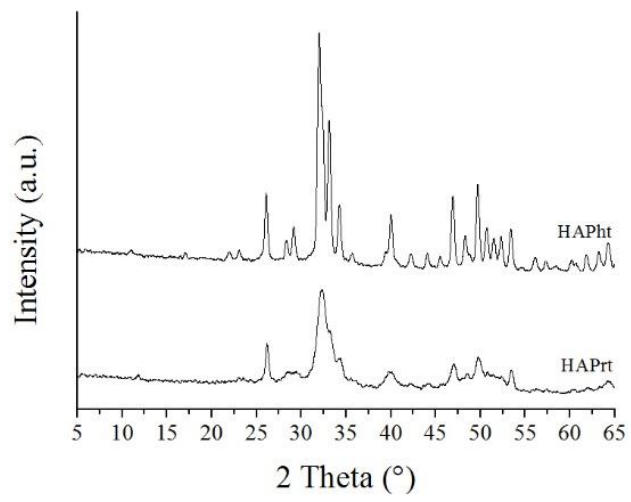


Figure 5

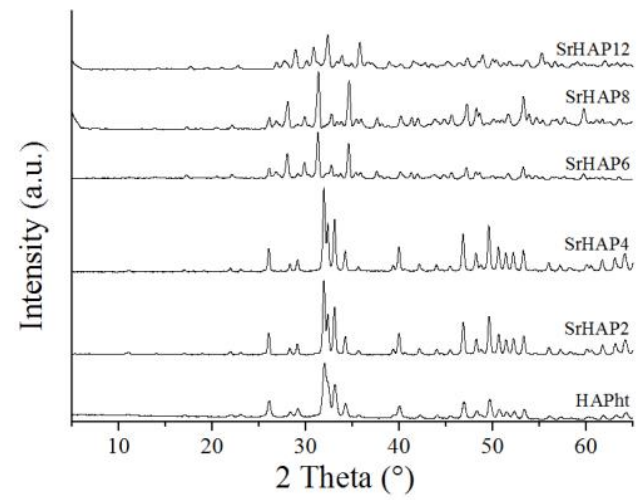


Figure 6

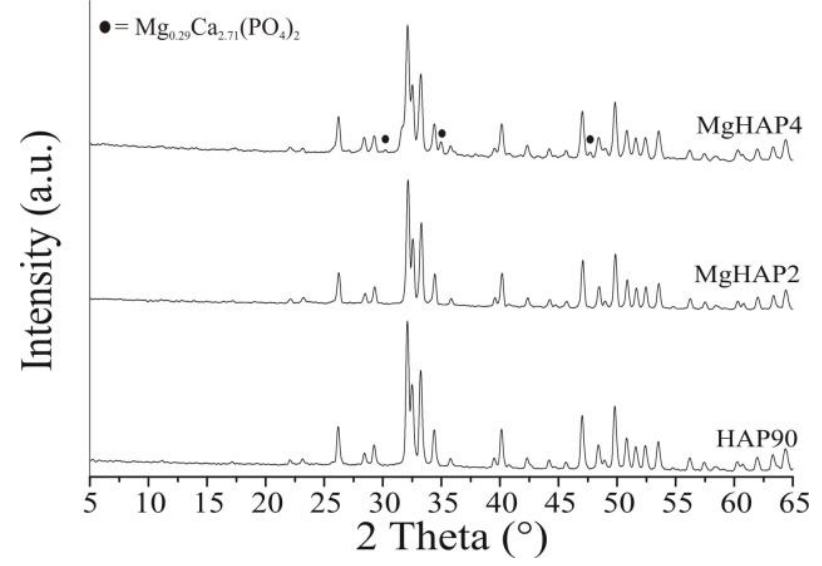


Figure 4
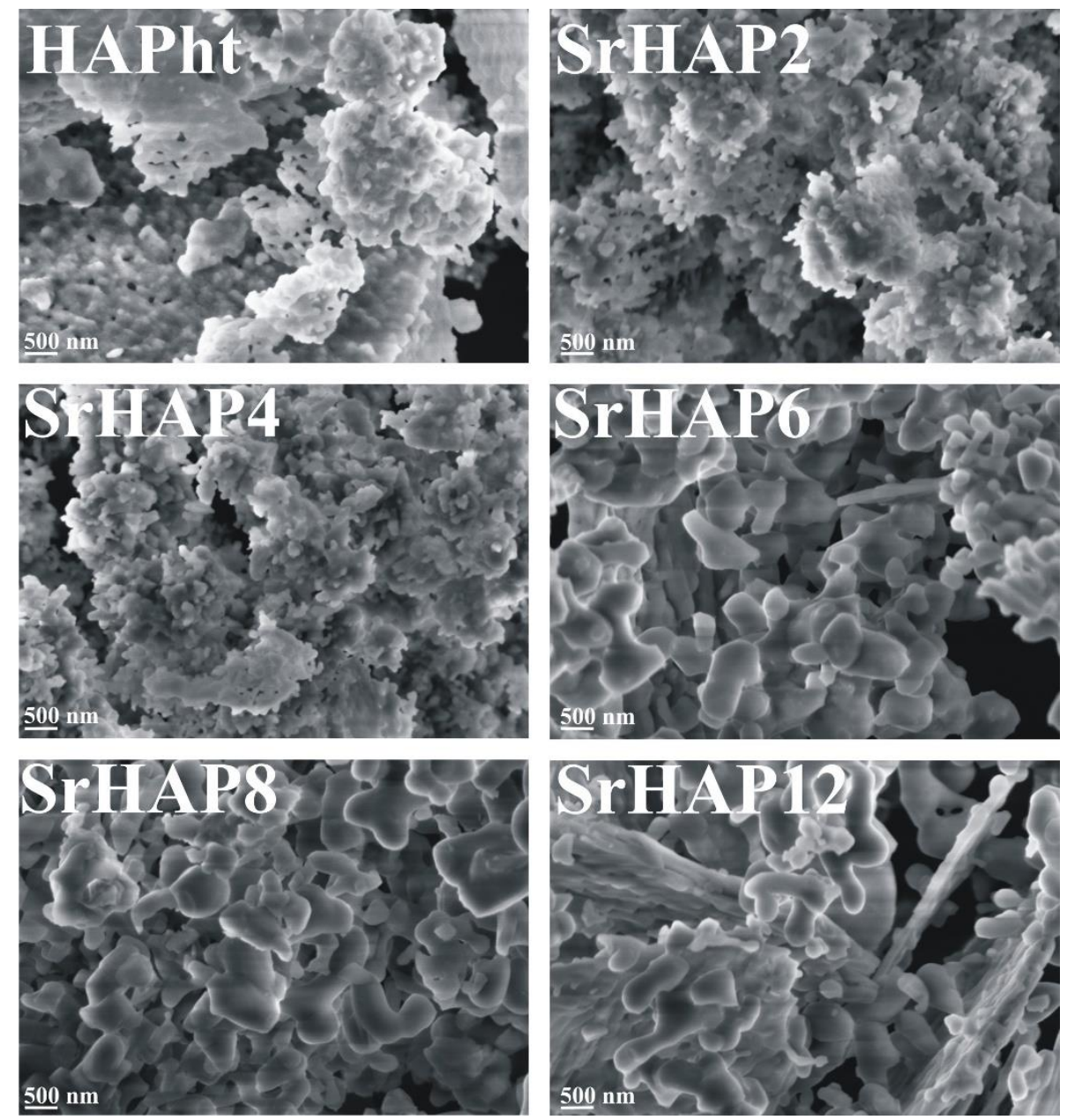
Figure 5
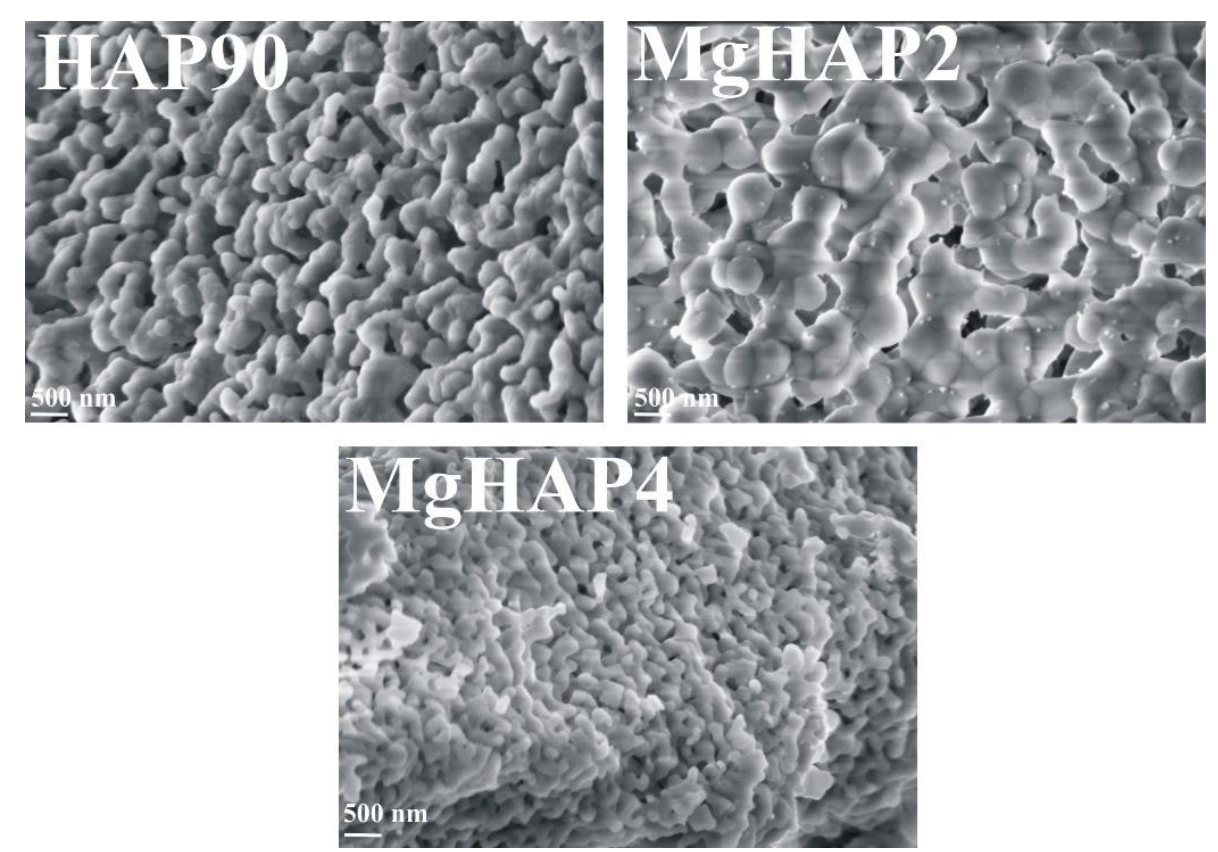
Figure 6

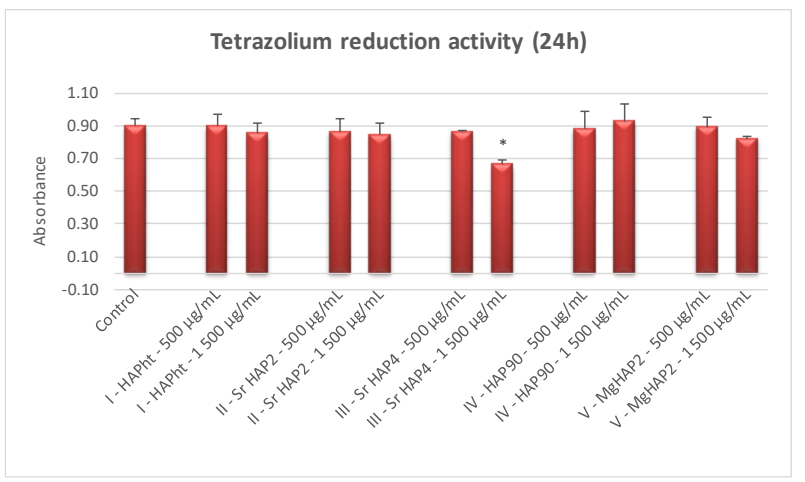

